\title{
ИЗУЧЕНИЕ РАСПРЕДЕЛЕНИЯ РЕГИОНОВ РОССИИ ПО УРОВНЮ ИНВЕСТИЦИОННОЙ АКТИВНОСТИ
}

\author{
(C) 2020 Вагин Сергей Геннадьевич \\ доктор экономических наук, профессор \\ Самарский государственный экономический университет, Россия, Самара \\ (c) 2020 Лисачкина Юлия Сергеевна \\ аспирант \\ Самарский государственный экономический университет, Россия, Самара
}

Тема инвестиционной активности регионов не только не утрачивает своей актуальности на протяжении последней четверти века, а наоборот становится сверх важной в условиях перехода России на цифровые технологии, который в свою очередь нуждается в значительных финансовых вливаниях в производстсво и инфраструктуру. В этой связи цель исследования состоит в количественном измерении и качественной интерпретации дифференциации регионов России по основным показателям инвестиционной деятельности. Для достижения поставленной цели использовались такие научные методы как табличный, графический, дескриптивные статистики и метод многомерных группировок. К основным результатам можно отнести следующее: выявлены три стадии развития инвестиционной активности в России - до 1998 года наблюдается рост, но уровни не пробивают отметки 100\%, далее 1999-2008 гг. прирост и с 2009 г. по настоящее время имеем снижение (убыль) инвестиций; на основе кластерного анализа выделены три группы субъектов РФ, которые характеризуются различными направлениями инвестирования и источниками поступления инвестиций. Полученные результаты будут полезны исследователям, в поле зрения которых входят вопросы инновационной активности регионов России и факторов оказывающие существенное воздействие на ее вариацию. Направление дальнейшего исследования видится в выделении и количественном измерении влияния социально-экономических факторов оказывающих влияние на инвестиционную активность в субъектах РФ.

Ключевые слова: пространственная экономика, регионы, инвестиции, группировка, факторы, распределение.

\section{Введение.}

Планомерное поступательное развитие, впрочем, как и скачкообразное изменение макроэкономических характеристики, немыслимо без значительных инвестиционных вложений. Особо остро проблема нехватки инвестиций возникает в периоды перехода на новую ступень развития, так в текущий период российская экономика активно внедряет цифровые технологии, при этом в стране наблюдаются негативные последствия валютного кризиса 2014 года, также дефицитные ресурсы идут на борьбу с пандемией вируса Covid-19. Все вышеперечисленное требует консолидации колоссального объема инвестиционных средств, поэтому считаем, что научная тема оценки инвестиционной активности регионов является актуальной задачей стоящей перед экономической наукой.

Рассмотрение теоретико-методологических и прикладных экономических исследований в области инвестиционной политики России и ее регионов приводит нас к следующим авторам:

Абрамова М.И. [1], Андреева М. В. [2], Берзон Н.И. [3], Колмыкова Т.С. [5], Красильникова Е.А. [6], Маковкина С.А. [7], Матюгина Э.Г. [8], Муллагалиева И.Ф. [9], Перова В.И. [10], Саблин К.С. [11], Скоморощенко А.А. [12], Толмачев М.Н. [13], Цыпин А.П. [14], Шабанникова Н.Н. [15]. В своих работах ученые рассматривали достаточно большой вектор проблем, от влияния социальноэкономических факторов на инвестиционный климат, до выделения групп регионов России со схожими характеристиками инвестиционного фона. Опираясь на мнения приведенных ученых, можно сформулировать цель настоящего исследования.

Итак, цель исследования состоит в количественном измерении и качественной интерпретация дифференциации регионов России по основным показателям инвестиционной деятельности., которая заключается в - количественном измерение и качественной интер- 
претации дифференциации регионов России по основным показателям инвестиционной деятельности.

Подготовка статистического материала осуществлялась на основе официальных сведений предоставляемых системой Росстата и публикуемые в общественном поле в форме статистических сборников, ежегодников, справочников и аналитических записок, таких как «Регионы России. Социально-экономические показатели», «Россия в цифрах» и «Инвестиции в России» за различные годы.

На основании сведений приведенных в указанных источниках был сформирован перечень показателей, отражающих инвестиционный фон в регионах России в 2018 г.

Приведенные на рисунке 1 будут обработаны с помощью ряда статистических методов: во-первых, табличный и графический, что позволит представить результаты исследования в наглядной и доступной форме; во-вторых, дескриптивные статистики, что позволит оценить изменения в динамике и структуре; в-третьих, многомерная группировка, что позволит выделить однородные группы регионов по уровню инвестиционной активности.

\section{Результаты исследования.}

На начальном этапе исследования, прежде чем непосредственно переходить к рассмотрению вариации показателей инновационной активности в региональном разрезе, обратимся к рисунку 2 и оценим динамику индекса физического объема инвестиций.

Динамика, приведенная на рисунке 2 проявляет три четко выраженных периода: во-первых, до 1998 г. наблюдается рост показателя, но значения не превышают 100\% уровня, данная траектория объясняется общеэкономической нестабильностью вследствие трансформационного перехода; во-вторых, период 1999-2008 гг., в котором наблюдается превышение уровня в $100 \%$, что достигалось благодаря высоким ценам на углеводороды на мировом рынке; в-третьих, период начавшийся с падения в 2009 году и продолжающийся по сегодняшний момент времени, он характеризуется понимающей траекторией. Таким образом, можно сделать вывод, что за последние 30 лет в России был всего один инвестиционно-благоприятный временной промежуток, в течение которого можно было формировать воспроизводимый капитал.

Инвестиции в основной капитал (G1), млн руб.

Инвестиции в основной капитал на душу населения (G2), руб.

Индекс физического объема инвестиций в основной капитал (G3), в \%

к предыдущему году

Удельный вес инвестиций на приобретение машин, оборудования,

транспортных средства (G4), \%

Удельный вес инвестиций на приобретение объектов

интеллектуальной собственности (G5), \%

Удельный вес инвестиций в форме кредиты банков (G6), \%

Доля инвестиций направленных в обрабатывающие производства

(G7), \%

Рисунок 1. Набор показателей характеризующих инвестиционный фон в регионах России 


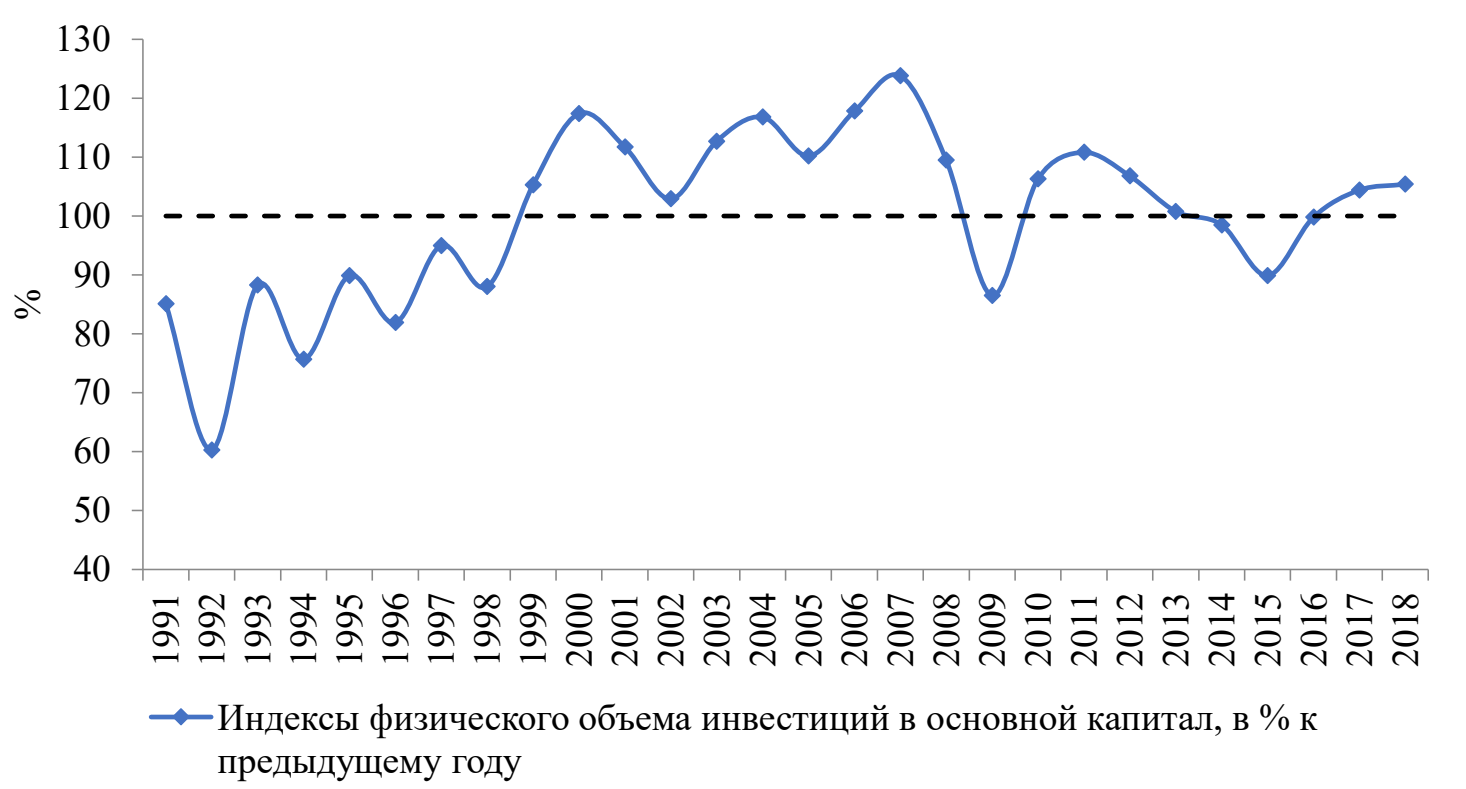

Рисунок 2. Изменения индекса физического объема инвестиций в России в 1991-2018 гг. (Источник: составлено на основе данных публикуемых в Российском статистическом ежегоднике)

Обратимся к данным приведенным в таблице 1 и проанализируем изменение инвестиций (на душу населения) в разрезе федеральных округов.

Данные приведенные в таблице 1 показывают, что на всем протяжении рассматриваемого периода наибольшее значение наблюдается в Уральском федеральном округе, данный факт объясняется незначительным числом жителей, при значительной плотности промышленных предприятий, которые являются как источником, так и потребителем инвестиций. Если рассматривать динамику изменения в отчетном году относительно предшествующего, то на первом месте стоит ЦФО с приростом в 14,6\%, для этого региона характерно наличие источников финансирования и потребителей инвестиций начиная от сферы гостеприимства заканчивая обрабатывающими производствами. Таким образом, наилучшие, на протяжении последних 15 лет наилучшие позиции занимают регионы с развитой обрабатывающей и добывающей промышленностью.

Далее проведем многомерную группировку, для этого используем иерархическую кластерпроцедуру (метод двухвходового объединения), при этом из рассмотрения исключим переменную G1 так как она не стандартизирована, а значит итоги анализа будет искажать эффект масштаба. В качестве меры объединения используем процедуру Уорда (Варда), при это расстояние до объектов до центра сгустка будет измерено с помощью Евклидова расстояния (рисунок 3).

Таблица 1. Изменение инвестиций в разрезе регионов России, тыс. руб. на душу населения

\begin{tabular}{|c|c|c|c|c|c|c|c|}
\hline $\begin{array}{c}\text { Регионы } \\
\text { России }\end{array}$ & 2005 & 2010 & 2015 & 2016 & 2017 & 2018 & $\begin{array}{c}\text { Темп роста } \\
\text { снижения) } \\
2018 / 2017, \%\end{array}$ \\
\hline РФ & 25,2 & 64,1 & 94,9 & 100,6 & 109,1 & 119,8 & 109,8 \\
\hline ЦФО & 25,3 & 54,7 & 91,7 & 96,9 & 108,0 & 123,8 & 114,6 \\
\hline СЗФО & 35,1 & 83,3 & 103,8 & 125,6 & 135,2 & 149,6 & 110,6 \\
\hline ЮФО & 17,7 & 65,5 & 79,4 & 70,3 & 87,8 & 85,5 & 97,4 \\
\hline СКФО & 10,4 & 33,4 & 49,1 & 49,9 & 50,6 & 56,0 & 110,5 \\
\hline ПФО & 19,9 & 48,0 & 83,0 & 82,2 & 82,1 & 83,7 & 102,0 \\
\hline УФО & 48,8 & 123,3 & 191,8 & 218,1 & 229,4 & 237,3 & 103,4 \\
\hline СФО & 17,7 & 50,9 & 71,6 & 74,8 & 80,4 & 91,5 & 113,9 \\
\hline ДФО & 42,5 & 125,0 & 145,9 & 161,7 & 186,2 & 169,9 & 91,3 \\
\hline
\end{tabular}

Источник: составлено на основе данных публикуемых в издании «Регионы России. Социальноэкономические показатели» 


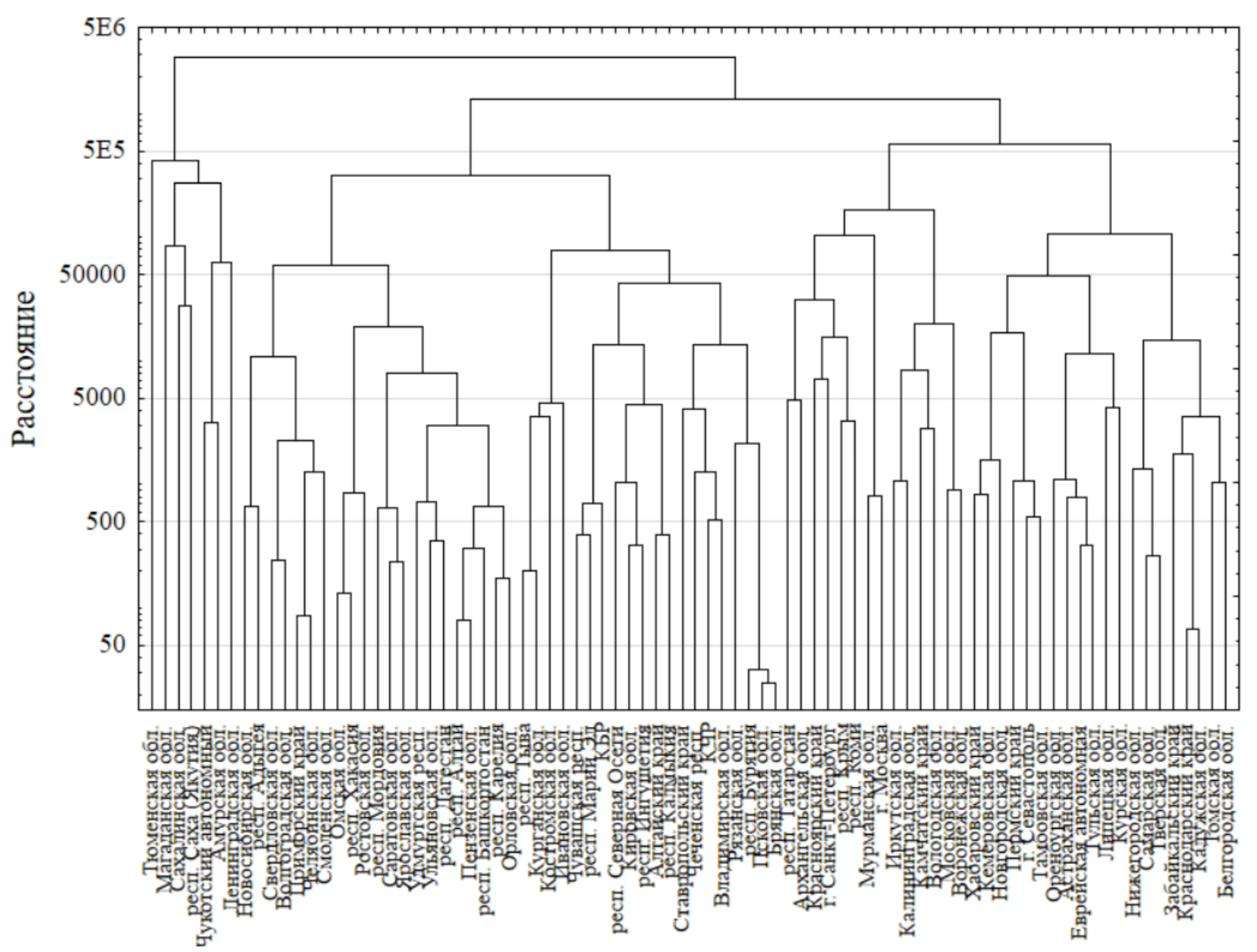

Рисунок 3. Диаграмма объединения субъектов РФ в отдельные кластеры на основе показателей инвестиционной активности за 2018 г.

(Источник: составлено на основе сведений издания «Регионы России. Социально-экономические показатели»)

Таблица 2. Дескриптивные статистики показателей инновационной активности для трех групп субъектов РФ в 2018 г.

\begin{tabular}{|c|c|c|c|c|c|c|}
\hline \multirow{2}{*}{ Показатели } & \multicolumn{2}{|c|}{ 1 кластер } & \multicolumn{2}{c|}{ 2 кластер } & \multicolumn{2}{c|}{3 кластер } \\
\cline { 2 - 7 } & средняя & \pm SE & средняя & \pm SE & средняя & \pm SE \\
\hline G2 & 387511,7 & 47432,9 & 56343,4 & 2014,8 & 115815,5 & 5422,8 \\
\hline G3 & 110,5 & 3,7 & 103,6 & 2,2 & 99,0 & 2,8 \\
\hline G4 & 27,3 & 5,0 & 37,6 & 1,5 & 38,4 & 1,7 \\
\hline G5 & 3,4 & 1,1 & 1,5 & 0,5 & 2,1 & 0,3 \\
\hline G6 & 8,0 & 3,5 & 7,9 & 1,1 & 9,2 & 1,3 \\
\hline G7 & 9,1 & 4,8 & 19,7 & 2,0 & 18,8 & 2,7 \\
\hline
\end{tabular}

Источник: рассчитано на основе сведений издания «Регионы России. Социально-экономические показатели». Примечание: SE - стандартная ошибка средней 
Приведенные результаты кластеризации (рисунок 3) указывают на наличие трех групп регионов в первый, самый малочисленный, вошли регионы, на долю которых приходится $22 \%$ всех инвестиций России, также по данной группе наблюдаются максимальные значения по показателям G2 и G5. В третьей кластер вошли субъекты РФ характеризующиеся высокими значениями инвестиций на приобретение оборудования (G4) и долей кредитных средств в инвестициях (G6). При этом более 55\% всего инвестиционного потока устремляется именно в эти регионы. Во второй кластер вошли объекты, характеризующиеся средними показателями.

Таким образом, анализ сведений приведенных в таблице 2 позволяет сделать вывод о неоднозначной ситуации в отношении распределения инвестиционных потоков, т.е. направление и источники финансовых вливаний во многом зависят от структуры региональной экономики.

\section{Заключение.}

Подводя итоги провеянного исследования можно сделать ряд выводов.

Во-первых, динамика индекса физического объема инвестиций в основной капитал указывает на три различных периода развития явления, при этом в текущем подпериоде наблюдается понижающий тренд, т.е. имеет место снижение инвестиционной активности.

Во-вторых, изучение вариации инвестиций по федеральным округам показал, что на протяжении последних 15 лет наилучший инвестиционный фон наблюдается в регионах с развитой обрабатывающей и добывающей промышленностью.

В-третьих, применение процедуры кластерного анализа, к показателям характеризующим инвестиционную активность регионов в 2018 г., показало наличие значительного расслоения субъектов РФ по их уровню, что обусловлено исторически сложившемся фактом концентрации финансовых источников и потребителей инвестиций.

\section{Библиографический список}

1. Абрамова М. И. Оценка инвестиционного климата региона // Экономическая безопасность и качество. 2019. № 1 (34). С. 38-43.

2. Андреева М.В., Кирик О.Б. Развитие кластерной политики как условие повышения инвестиционной активности в регионе // Инновационная экономика: перспективы развития и совершенствования. 2020. № 4 (46). C. 4-12.

3. Берзон Н. И. Банковский сектор России: вызовы, проблемы и перспективы // Финансы и бизнес. 2016 . № 3. С. 35-46.

4. Вагин С.Г. Концептуальные пути формирования стратегии развития региональной экономики // Вестник Самарского государственного экономического университета. 2013. № 12 (110). С. 24-27.

5. Колмыкова Т.С., Приходько Ю.Н., Астапенко Е. О. Исследование инвестиционной активности экономики региона // Регион: системы, экономика, управление. 2019. № 3 (46). С. 16-22.

6. Красильникова Е.А., Никишин А. Ф.Интегральные показатели прогнозирования инвестиционной активности регионов // Бизнес. Образование. Право. 2019. № 1 (46). С. 197-201.

7. Маковкина С.А., Воронов Н.Д. Влияние цифровой трансформации на инвестиционную привлекательность региона // Муниципалитет: экономика и управление. 2019. № 4 (29). С. 95-103.

8. Матюгина Э.Г., Клабукова А. А. Инновационная активность и инвестиционная привлекательность региона в аспекте его конкурентоспособности // Экономика: вчера, сегодня, завтра. 2020. Т. 10. № 2-1. С. 300-306.

9. Муллагалиева И. Ф. Повышение инвестиционной активности регионов Российской Федерации // Научный электронный журнал Меридиан. 2020. № 3 (37). С. 54-56.

10. Перова В.И., Папко А.В.Нейросетевой анализ динамики инвестиционной деятельности регионов Российской Федерации // Вестник Нижегородского университета им. Н.И. Лобачевского. Серия: Социальные науки. 2019. № 1 (53). С. 24-32.

11. Саблин К.С., Каган Е.С., Чернова Е. С. Кластеризация угледобывающих регионов России: инвестиционная и инновационная активность // Journal of New Economy. 2020. Т. 21. № 1. С. 89-106.

12. Скоморощенко А.А. Инструменты стимулирования инвестиционной активности в регионе // Московский экономический журнал. 2019. № 12. С. 29. 
13. Толмачев М.Н.Дифференциация регионов по уровню экономического развития // Вестник Института дружбы народов Кавказа (Теория экономики и управления народным хозяйством). Экономические науки. 2011. № 1 (17). С. 28-35.

14. Цыпин А.П., МорозоваС.Н.Изучение влияния макроэкономических факторов на инвестиции в регионах России // Финансовая экономика. 2018. № 4. С. 390-394.

15. Шабанникова Н. Н. Анализ и направления повышения инвестиционной активности экономических субъектов региона // Вестник аграрной науки. 2020. № 6 (87). С. 175-183. 